\title{
The Differential Salience of Family and Community Demands and Resources for Family-to-Work Conflict and Facilitation
}

\author{
Patricia Voydanoff \\ University of Dayton
}

\begin{abstract}
This paper examines the differential salience of family and community demands and resources in relation to family-to-work conflict and facilitation. The study used interviews with 1567 employed, married, parents from the 1995 National Survey of Midlife Development (MIDUS). Family demands show relatively strong positive relationships to family-to-work conflict, whereas family resources are relatively important for family-to-work facilitation. Two community demands are positively related to family-to-work conflict and one community resource is positively associated with facilitation. Community demands and resources generally do not moderate relationships between family demands and resources and family-to-work conflict and facilitation. The study suggests that processes associated with demands are relatively important for family-to-work conflict, whereas processes embedded in resources are relatively salient for family-to-work facilitation.
\end{abstract}

KEY WORDS: community demands and resources; family demands; family resources; family-to-work conflict; family-to-work facilitation.

Research over the past few decades has revealed that work and family are inter-connected domains. When the boundaries between the work and family domains are sufficiently permeable and flexible, processes occur through which characteristics associated with one domain influence the other domain. Work-family conflict and facilitation are linking mechanisms in the processes through which work and family characteristics are related to individual, work, and family outcomes (Voydanoff, 2002). They are cognitive appraisals of the effects of one domain on the other domain. Lazarus and Folkman (1984) state that cognitive appraisal is the process of deciding whether an experience is positive, stressful, or irrelevant with regard to wellbeing. Stressful appraisals occur when individuals perceive that the demands of their environment exceed their resources and endanger

Patricia Voydanoff, Fitz Center for Leadership in Community, University of Dayton, Dayton, OH 45469-1445; e-mail: Patricia.Voydanoff@notes.udayton.edu. 
their well-being. Thus, the perception of work-family conflict or facilitation derives from assessing the relative demands and resources associated with work and family roles. Demands are structural or psychological claims associated with role requirements, expectations, and norms to which individuals must respond or adapt by exerting physical or mental effort. Resources are structural or psychological assets that may be used to facilitate performance, reduce demands, or generate additional resources (Demerouti, Bakker, Nachreiner, \& Schaufeli, 2001).

Work-family conflict is a form of inter-role conflict in which the demands of work and family roles are incompatible in some respect so that participation in one role is more difficult because of participation in the other role (Greenhaus \& Beutell, 1985). This conflict can take two forms: work-to-family conflict in which the demands of work make it difficult to perform family responsibilities and family-to-work conflict in which family demands limit the performance of work duties. Work-family facilitation is less established as a concept than workfamily conflict, going by various labels and definitions. (see Greenhaus \& Powell, in press, for a review). Work-family facilitation is a form of synergy in which resources associated with one role enhance or make easier participation in the other role. It also can operate from either work to family or family to work. The resources associated with the work domain may facilitate the performance of family duties and activities, whereas family resources may enhance job performance.

Family-to-work conflict and facilitation are only slightly correlated with each other. One study of all employed respondents from the sample used in this study reported that family-to-work conflict and facilitation are not correlated $(r=-.04)$ and form separate factors in factor analyses (Grzywacz \& Marks, 2000), whereas other studies reported correlations of .00 (Montgomery, Peeters, Schaufeli, \& Den Ouden, 2003) and -.10 (Sumer \& Knight, 2001). Thus, family-to-work conflict and family-to-work facilitation are independent constructs rather than being opposite ends of a single continuum.

Previous research has focused on work-to-family conflict as the cognitive linking mechanism between work and family characteristics and outcomes, whereas family-to-work conflict and facilitation have been relatively neglected. This imbalance may hinder the development of more comprehensive theories of work-family linkages as well as provide a limited view of the policies and programs that could reduce work-family conflict and enhance work-family facilitation. Documenting the effects of family demands and resources on both conflict and facilitation has implications for understanding the work 
and family outcomes that work-family programs and policies are designed to address.

Recently, scholars have begun to consider that demands and resources other than work and family characteristics also may influence the ability of individuals and families to fulfill their work and family responsibilities. These may include a range of structural and psychological demands located in the community (see, e.g., Voydanoff, 2004b). Structural demands and resources in the community always have influenced the work-family interface, for example, the availability of child care services in the community and the lack of fit between work hours and school hours. In addition, recent changes occurring in the work, community, and family domains are blurring the boundaries that differentiate one from another and resulting in overlapping networks and obligations associated with work, community, and family life. These changes are associated with psychological demands and resources in the community that may influence familyto-work conflict and facilitation, for example, the presence or absence of community integration, neighborhood safety and cohesion, and friend-based demands and supports. Understanding how family and community demands and resources combine to influence family-towork conflict and facilitation provides a necessary foundation for designing work and community policies and programs that reduce family-to-work conflict and increase family-to-work facilitation.

Research on the effects of psychologically based family and community demands and resources on family-to-work conflict and facilitation is sparse. Using all employed members of the sample used in this study, Grzywacz and Marks (2000) investigated spouse support and kin demands and support in relation to family-to-work conflict and facilitation. However, they did not consider spouse demands, parenting or household demands and resources, or community demands and resources. Because of the focus on marital and parental roles, this study uses the sub-sample of employed and married parents. This study incorporates these additional family demands and resources and includes community demands and resources.

The study also extends two recent studies by Voydanoff (2004a, c), who has examined the differential salience of work and community demands and resources for work-to-family conflict and facilitation. She reports that work and community demands are relatively strongly related to work-to-family conflict, whereas work and community resources are relatively more important in relation to work-to-family facilitation. The conceptualization of work-family conflict and previous research indicate that work demands are related to work-to-family 
conflict, whereas family demands are related to family-to-work conflict (see, e.g., Frone, Yardley, \& Markel, 1997). Because of the complexities involved in assessing the effects of demands and resources associated with multiple types of family relationships, namely, marital, parental, and extended kin, and the incomparability of sample sizes with all employed respondents, the effects of family and community demands and resources on family-to-work conflict and facilitation are presented separately in this paper rather than being combined with the previous analysis of work and community demands and resources in relation to work-to-family conflict and facilitation.

The present study examines demands and resources from four aspects of family life (marital, household, parental, and kin roles) and three aspects of community life (community as a whole, neighborhood, and friends) in relation to family-to-work conflict and facilitation. Few studies have examined a wide range of family demands and resources in relation to family-to-work conflict. Even fewer have looked at relationships between demands and resources and family-to-work facilitation. None have viewed the effects of community demands and resources on family-to-work conflict or facilitation. This study expands on previous research by examining the relative salience of a range of family and community demands and resources in relation to both family-to-work conflict and facilitation for large representative sample of employed, married, parents.

\section{Family and Community Demands and Family-to-Work Conflict and Facilitation}

Based on the differential salience approach developed by Voydanoff (2004c), family and community demands and resources are expected to be differentially salient in relation to family-to-work conflict and facilitation. This differential salience approach proposes that family and community demands are positively related to family-to-work conflict, whereas family and community resources are positively associated with family-to-work facilitation. Family and community demands are relatively salient for family-to-work conflict because they are associated with processes that limit the ability of individuals to meet obligations in another domain. Family and community resources are relatively salient for family-to-work facilitation because they engender processes that improve performance when they are applied across domains. The different processes associated with the effects of demands and resources on conflict and facilitation suggest that 
demands are not likely to be strongly related to facilitation, whereas resources are unlikely to show strong associations with conflict. In addition, community demands may exacerbate the effects of family demands on family-to-work conflict, whereas community resources may amplify the positive relationships between family resources and family-to-work facilitation. These proposed relationships are summarized in Figure 1.

\section{Family Demands}

Family demands are associated with processes that lead to family-towork conflict. These demands are of two types: time-based and strainbased. Because of limitations in the data set, this study focuses on

\section{FIGURE 1}

\section{Differential Salience Model of Family to Work Conflict and Facilitation}
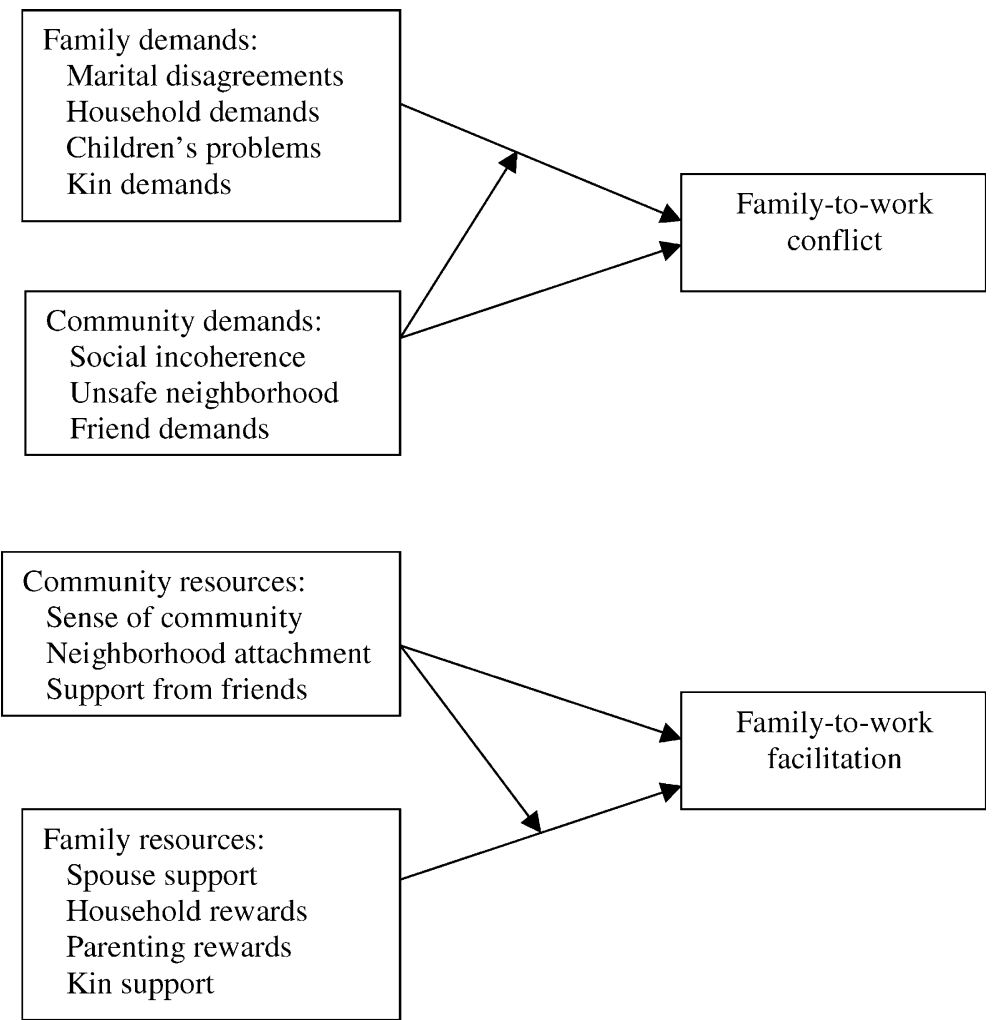
strain-based demands. Strain-based demands are linked to family-towork conflict through a process of psychological spillover in which the strain associated with participating in one domain is carried over to another domain such that it creates strain in the second domain, thereby hindering role performance in that domain. Psychological spillover operates through transmission processes in which family conditions are associated with psychological responses, which are then transferred into attitudes and behaviors at work. Negative transmission processes include negative emotional arousal, inter-personal withdrawal, energy depletion, and stress (Piotrkowski, 1979; Rothbard, 2001).

Strain-based family demands that influence the work-family interface may derive from four components of family roles and activities: spouse demands, household demands, children's problems, and kin demands. No known studies have examined spouse demands in relation to family-to-work conflict. Household demands were positively related to family-to-work conflict in three studies (Boyar \& Maertz, 2003; Kowalski \& Beauvais, 2001; Montgomery et al., 2003) but not in another (Carlson \& Kacmar, 2000). Problems associated with children and parenting were positively associated with family-to-work conflict in one study (Frone et al., 1997), and positively related to conflict for men but not for women in another study (Beauregard, 2002). Kin demands were positively related to family-to-work conflict in a study based on all employed respondents from the sample used in this study (Grzywacz \& Marks, 2000).

However, the differential salience approach suggests that family demands are likely to be less salient for family-to-work facilitation because facilitation is expected to result from resources that mobilize or engage individuals rather than from a lack of demands. Because spillover processes generally create similarities across domains (Edwards \& Rothbard, 2000), it is unlikely that strain-based family demands will be strongly associated with family-to-work facilitation. No known studies have examined spouse demands or children's problems in relation to family-to-work facilitation. Household demands showed a weak negative relationship to family-to-work facilitation in one study (Montgomery et al., 2003), whereas kin demands were negatively related to family-to-work facilitation for women but not for men in another (Grzywacz \& Marks, 2000).

\section{Community Demands}

Community demands and resources differ from work demands and resources in that they originate outside of the work and family 
domains. The extent to which they influence family-to-work conflict and facilitation depends on the permeability and flexibility of the boundaries among the three domains. Including community demands and resources in a test of the differential salience approach presumes enough permeability and flexibility that some carryover from community to the work-family interface exists. However, it is not expected that the community demands and resources will be as strongly related to family-to-work conflict and facilitation as family demands and resources are.

The community demands and resources included in the study draw from three aspects of community: the community as a whole, the neighborhood as a local geographic community, and friends who serve as a major source of primary group interaction outside the family. The community demands are strain-based demands that focus on negative perceptions of community life that may spill over to the work-family interface such that they limit workers' ability to address family demands without experiencing family-to-work conflict. As discussed above, this spillover may involve the transmission of negative emotions, stress, energy depletion, and inter-personal unavailability. Social incoherence, the opposite of social coherence as defined by Keyes (1998), extends beyond the local community to incorporate appraisals that society is not discernable, sensible, and predictable. Such perceptions and lack of grounding may operate as a stressor that influences family-to-work conflict. The perception of living in an unsafe neighborhood is another potential stressor that may carry over to the work-family interface by serving as a concern, distraction, or a problem requiring concerted effort. High levels of personal and emotional demands from friends also may reduce the ability of workers to deal with the demands presented by their families, thereby increasing the likelihood of family-to-work conflict. According to the differential salience approach, these demands may have less effect on family-towork facilitation because they are not connected to the processes through which family and community resources create family-to-work facilitation, namely enabling family members by generating useful resources or providing psychological rewards. No known studies have investigated such relationships.

In addition to additive effects of family and community demands on family-to-work conflict, community demands may exacerbate the negative effects of family demands on conflict. It is possible that family demands are more strongly related to family-to-work conflict for those who experience high levels of community demands. Since so little is known in this area, both types of relationships are examined. 


\section{Family and Community Resources and Family-to-Work Facilitation and Conflict}

\section{Family Resources}

Theoretical and empirical study of work-family facilitation is much more limited than that for work-family conflict. The differential salience approach suggests that demands are related to work-family conflict, whereas the focus in work-family facilitation is on resources. Resources are associated with motivation and energy mobilization that improve performance. Resources are of two types: enabling resources and psychological rewards. Enabling resources from one domain may generate resources in another domain that provide the means for enhancing participation in the second domain. Enabling resources generally are associated with the structure or content of domain activities, for example, skills and abilities developed through domain activity and the availability of social support from others involved in the domain. Enabling resources contribute to work-family facilitation by increasing the competence and capacities of individuals to perform across domains.

Resources also include psychological rewards that are associated with feeling esteemed and valued. These rewards may be accompanied by psychological benefits, such as motivation, a sense of accomplishment, self-esteem, and ego gratification. They may be related to family-to-work facilitation through transmission processes in which family conditions are associated with psychological responses, which are then transferred into attitudes and behaviors at work. Positive transmission processes include positive emotional arousal, inter-personal availability, energy creation, and gratification (Piotrkowski, 1979; Rothbard, 2001).

This study includes spouse and kin support as enabling resources and household and parenting rewards as psychological rewards. Spouse and kin support provide empathy, understanding, and assistance that may enable individuals to perform better across domains. Spouse and kin support are positively related to family-to-work facilitation for the employed respondents from the sample used in this study (Grzywacz \& Marks, 2000). Household and parenting rewards provide recognition and a sense of pride, such as being respected for the unpaid work done at home and pride associated with parenting, which may create positive psychological spillover into other domains. No known studies have examined relationships between household and parenting rewards and family-to-work facilitation. 
Based on the differential salience approach, family resources are expected to be relatively less important for family-to-work conflict than for facilitation. Enabling resources may reduce family-to-work conflict somewhat, but not to the extent that they increase family-towork facilitation. The few studies that have examined enabling resources in relation to family-to-work conflict report that spouse support shows a modest negative relationship to family-to-work conflict, whereas kin support is not related to family-to-work conflict in one study and is negatively related to conflict in another study (Adams, King, \& King, 1996; Grzywacz \& Marks, 2000). The similarities created across domains by psychological spillover reduce the likelihood that psychological rewards are strongly related to family-towork conflict. Only one study was located that addressed relationships between psychological rewards and family-to-work conflict. Beauregard (2002) reported that household rewards are not related to familyto-work conflict.

\section{Community Resources}

The community resources included in the present study are aspects of social integration. Social integration generally is defined as structural or affective inter-connectedness with others and with social institutions. It encompasses patterns of social interaction and participation and attitudes regarding institutions and relationships. Three types of social integration based on affective connections are considered here: sense of community, neighborhood attachment, and support from friends. They incorporate the three aspects of community life considered in relation to community demands, i.e., the community as a whole, the neighborhood as geographic community, and friends as a primary group. McMillan and Chavis (1986) state that sense of community consists of four inter-related elements: feeling of belonging, the sense that the individual and the group matter to each other, the feeling that members' needs will be met through group resources, and a shared history. Attitudinal neighborhood attachment is associated with neighborhood ties, trust, pride, and satisfaction (Woldoff, 2002). Support from friends is one type of informal social support, which may include resources such as emotional support, instrumental support, and support in the form of advice or information.

These three aspects of social integration are enabling resources that encompass social and psychological assets such as a sense of community belonging and support, a neighborhood that provides social order 
and support, and assistance and understanding from caring friends. These resources provide social embeddedness, social control and regulation, individual and group identity, inter-personal connections and attachment, access to other resources and support, and emotional sustenance. According to the differential salience approach, these resources facilitate the efforts of individuals and families to fulfill their work and family responsibilities so that family-to-work facilitation is increased. They provide additional enabling resources and support that work together with family resources to create family-to-work facilitation. However, it is not clear whether community resources also may lower family-to-work conflict. The resources generated from social integration may reduce family-to-work conflict somewhat, but not to the extent that they increase family-to-work facilitation. Previous research has not explored these community resources in relation to family-to-work facilitation or conflict.

If community resources contribute to family-to-work facilitation independently of family resources, as stated above, they would serve as independent enhancing factors. In addition, community resources may amplify the positive effects of family resources on family-to-work facilitation. In this case, family resources would be more strongly related to family-to-work facilitation for those with high levels of community resources. Because no research is available to establish the relative validity of these hypotheses, both are examined.

The differential salience approach and previous research suggest the following:

Hypothesis 1a: Family demands will be positively related to familyto-work conflict, whereas they will be unrelated to or show weak negative relationships to family-to-work facilitation.

Hypothesis 1b: Community demands will be positively related to family-to-work conflict, whereas they will be unrelated to or show weak negative relationships to family-to-work facilitation.

Hypothesis 1c: Community demands will exacerbate positive relationships between family demands and family-to-work conflict.

Hypothesis 2a: Family resources will be positively related to familyto-work facilitation, whereas they will be unrelated to or show weak negative relationships to family-to-work conflict.

Hypothesis 2b: Community resources will be positively related to family-to-work facilitation, whereas they will be unrelated to or show weak negative relationships to family-to-work conflict.

Hypothesis 2c: Community resources will amplify positive relationships between work resources and work-to-family facilitation. 


\section{Method}

\section{Data}

The study is a secondary analysis of data from the 1995 National Survey of Midlife Development in the U.S. (MIDUS), a nationally representative random-digit-dial sample of non-institutionalized English-speaking adults, aged 25-74, selected from working telephone banks in the coterminous United States. Respondents participated in a telephone interview with a response rate of $70 \%$ and a mail questionnaire with a response rate of $87 \%$, which yielded an overall rate of $61 \%$ for both parts of the survey. The sub-sample used in the analysis includes the 1567 respondents who are employed, are married or live with a partner, and are parents. Sixty percent of the sample is male, $90 \%$ is White, the mean age is 46 years, and the average level of education is three or more years of college with no degree. Twenty-four percent of the respondents have a child under six, whereas 32\% have a child between the ages of 7 and 13 .

\section{Measures}

Family-to-work conflict and facilitation. The measure of family-to-work conflict is the mean response to four items $(\alpha=.80)$ asking respondents how often in the past year they have experienced the following: "responsibilities at home reduce the effort you can devote to your job; personal or family worries and problems distract you when you are at work; activities and chores at home prevent you from getting the amount of sleep you need to do your job well; and stress at home makes you irritable at work". Responses ranged from $1=$ never to $5=$ all the time. Family-to-work facilitation is the mean response to three items $(\alpha=.70)$ asking respondents how often in the past year they experienced the following: "talking with someone at home helps you deal with problems at work"; "the love and respect you get at home makes you feel confident about yourself at work"; and "your home life helps you relax and feel ready for the next day's work". Responses ranged from $1=$ never to $5=$ all the time.

Family demands. The measure of marital disagreements is the mean response to three items $(\alpha=.74)$ asking respondents how much they and their spouse or partner disagree on the following issues: "money matters, such as how much to spend, save or invest"; "household tasks, such as what needs doing and who does it"; and "leisure time activities, such as what to do and with whom" ( 1 = not at all to $4=$ a lot). Household demands are assessed by the mean response to the following four questions $(\alpha=.70)$ : "In the past year, how often has each of the following occurred at home: you have too many demands made on you; you control the amount of time you spend on tasks (reverse coded); you have enough time to get everything done (reverse coded); and you have a lot of interruptions" ( $1=$ never to $5=$ all the time). The measure of children's problems is the sum of yes responses to a series of questions asking respondents whether any of their children had experienced the following seven problems in the past 12 months: chronic disease or disability, frequent minor illnesses, emotional problems, alcohol or substance problems, problems at school or at work, legal problems, and difficulty getting along with 
people (coded 0-5). Kin demands are assessed by the mean response to the following four items $(\alpha=.79)$ that were adapted from Schuster, Kessler, and Aseltine (1990): "Not including your spouse or partner, how often do members of your family make too many demands on you; how often do they criticize you; how often do they let you down when you are counting on them; how often do they get on your nerves?" ( $1=$ never to $4=$ often $)$.

Community demands. The measure of social incoherence is the average response to two questions $(\alpha=.65)$ from Keyes (1998) asking respondents how strongly they agree or disagree with the following: "The world is too complex for me" and "I cannot make sense of what's going on in the world" ( 1 = strongly disagree to $7=$ strongly agree). The measure, unsafe neighborhood, is the mean response to two questions $(\alpha=.73)$ from Keyes (1998) asking respondents the extent to which they feel safe being out alone in their neighborhoods during the daytime or at night. Responses ranged from $1=$ a lot to $4=$ not at all. Friend demands is measured by averaging answers to the following four questions $(\alpha=.79)$ adapted from Schuster et al. (1990): "How often do your friends make too many demands on you? How often do they criticize you? How often do they let you down when you are counting on them? How often do they get on your nerves?" ( 1 = never to $4=$ often $)$.

Family resources. Spouse support is assessed by averaging responses to six questions $(\alpha=.92)$ adapted from Schuster et al. (1990): "How much does your spouse or partner really care about you? How much does he or she understand the way you feel about things? How much does he or she appreciate you? How much can you rely on him or her for help if you have a serious problem? How much can you open up to him or her if you need to talk about your worries? How much can you relax and be yourself around him or her?" $(1=$ not at all to $4=\mathrm{a}$ lot). The measure of household rewards is the mean response to two questions $(\alpha=.81)$ asking respondents to what extent the following describe the way they feel about the unpaid work they do at home: "When I think about the work I do at home, I feel a good deal of pride" and "I feel that others respect the work I do at home" ( $1=$ not at all to $4=$ a lot $)$. Parenting rewards are assessed by the mean response to the following three items $(\alpha=.79)$ : "I feel good about the opportunities I have been able to provide for my children"; "I believe I have been able to do as much for my children as other people"; and "I feel a lot of pride about what I have been able to do for my children" ( 1 = not at all true to 4 =extremely true). The measure of kin support is the mean response to four questions $(\alpha=.84)$ adapted from Schuster et al. (1990): "Not including your spouse or partner, how much do members of your family really care about you? How much do they understand the way you feel about things? How much can you rely on them for help if you need to talk about your worries? How much can you open up to them if you need to talk about your worries?" ( $1=$ not at all to $4=\mathrm{a}$ lot $)$.

Community resources. Sense of community is the mean response to three questions $(\alpha=.73)$ from Keyes (1998) asking respondents how strongly they agree with the following: "I don't feel I belong to anything I'd call a community (reverse coded); I feel close to other people in my community; My community is a source of comfort" ( 1 = strongly disagree to $7=$ strongly agree). The measure of neighborhood attachment is the average of four items $(\alpha=.79)$ from Keyes (1998) asking respondents how much the following describes their situation: "I 
could call on a neighbor for help if I needed it; People in my neighborhood trust each other; I feel very good about my home and my neighborhood; My neighborhood is kept clean" ( $1=$ not at all to $4=$ a lot $)$. Support from friends is assessed by averaging responses to the following four questions $(\alpha=.88)$ adapted from Schuster et al. (1990): "How much do your friends really care about you? How much do they understand the way you feel about things? How much can you rely on them for help if you have a serious problem? How much can you open up to them if you need to talk about your worries?" ( 1 = not at all to $4=\mathrm{a}$ lot). Factor analysis of the items used in the scales indicates that each item has loading of at least .60 on the appropriate scale and, with the exception of the neighborhood attachment items, no loadings greater than .25 on other scales.

Demographic characteristics. Gender is a dummy variable coded 1 for male. Education is coded in 12 categories ranging from $1=$ no school or some grade school to 12 = professional degree. The presence of young children in the household is assessed a by dummy variable coded 1 if there was a child 6 years or younger present.

\section{Results}

Table 1 presents the zero-order correlations, means, standard deviations, and $\alpha$-coefficients of reliability for the variables in the analysis. The means reveal low family-to-work conflict and moderate family-to-work facilitation. The low correlation between conflict and facilitation (-.16) supports previous research, which indicates that conflict and facilitation are separate constructs. The correlations among predictors generally are low. However, a few are over .40. These include age and a child 6 or younger, marital disagreements and spouse support, kin and friend demands, and unsafe neighborhood and neighborhood attachment. With one exception, the $\alpha$-coefficients of reliability are .70 or higher. The $\alpha$-coefficient for the social incoherence scale is somewhat low at .65 .

The hypotheses are tested through ordinary least squares regression analysis. Tables 2 and 3 present the findings for family-to-work conflict and facilitation respectively. Model 1 includes the demographic characteristics, Models 2 and 3 add the coefficients for family and community demands, which are followed by family and community resources in Models 4 and 5 and the interaction terms in Model 6.

Tests for the interaction effects predicted in Hypotheses 1c and 2c were conducted in two stages. First regression analyses were performed that included demographic characteristics, one family or community demand, one family or community resource, and the crossproduct term of the family demand or resource and the community 


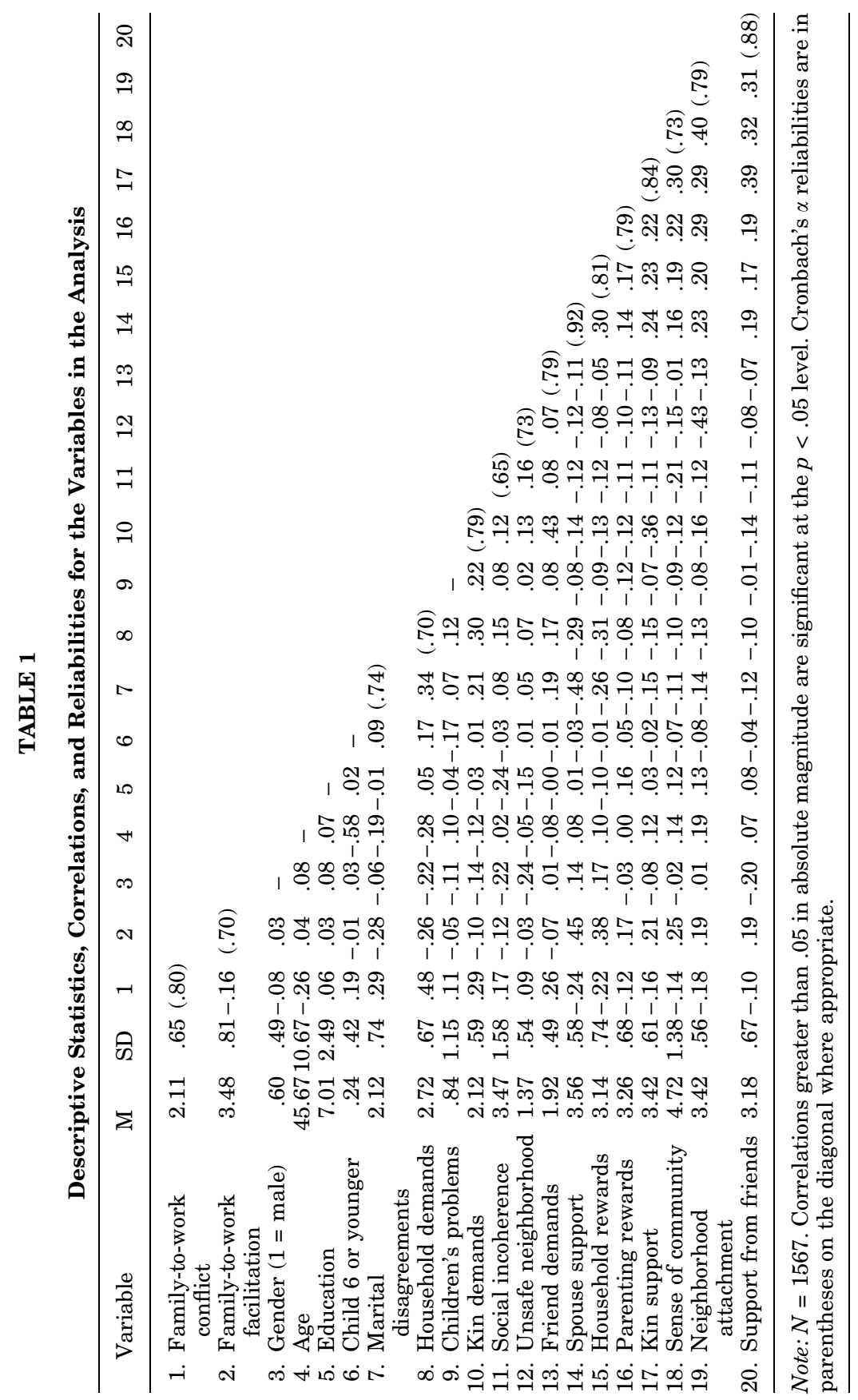




\section{TABLE 2}

Regressions of Family-to-Work Conflict on Demographic Characteristics, Family and Community Demands, and Family and Community Resources $(N=1567)$

Model 1 Model 2 Model 3 Model 4 Model 5 Model 6

\begin{tabular}{|c|c|c|c|c|c|c|}
\hline \multicolumn{7}{|l|}{ Demographic characteristics } \\
\hline Gender $(1=$ male $)$ & $-.06^{*}$ & .04 & $.06^{* *}$ & $.07 * *$ & $.07 * *$ & $.07 * *$ \\
\hline Age & $-.23 * * *$ & $-.10 * * *$ & $-.11 * * *$ & $-.11 * * *$ & $-.10 * * *$ & $-.10 * * *$ \\
\hline Education & $.08^{* *}$ & $.06^{*}$ & $.09 * * *$ & *. $.09 * * *$ & $.09 * * *$ & $.09 * * *$ \\
\hline Child 6 or younger $(1=$ yes $)$ & .05 & $.07 *$ & $.07 * *$ & $.07 * *$ & $.07 * *$ & $.07 * *$ \\
\hline \multicolumn{7}{|l|}{ Family demands } \\
\hline Marital disagreements & & $.11^{* * * *}$ & $.10 * * *$ & $.07 *$ & $.07 *$ & $.07 *$ \\
\hline Household demands & & $.36 * * *$ & $.34 * * *$ & $.32^{* * * *}$ & $.33 * * *$ & $.33 * * *$ \\
\hline Children's problems & & $.09 * * *$ & $.08 * * *$ & $.07 * *$ & $.07 * *$ & $.07 * *$ \\
\hline Kin demands & & $.15^{* * *}$ & $.09^{* * * *}$ & $.10^{* * *}$ & $.10^{* * *}$ & $.10^{* * * *}$ \\
\hline \multicolumn{7}{|l|}{ Community demands } \\
\hline Social incoherence & & & $.11^{* * * *}$ & $.11^{* * *}$ & $.11 * * *$ & $.11^{* * *}$ \\
\hline Unsafe neighborhood & & & .04 & .03 & .03 & .03 \\
\hline Friend demands & & & $.13^{* * * *}$ & $.12^{* * *}$ & $.12 * * *$ & $.12^{* * * *}$ \\
\hline \multicolumn{7}{|l|}{ Family resources } \\
\hline Spouse support & & & & $-.06^{*}$ & $-.06 *$ & $-.06^{*}$ \\
\hline Household rewards & & & & -.03 & -.03 & -.03 \\
\hline Parenting rewards & & & & -.04 & -.03 & -.03 \\
\hline Kin support & & & & .03 & .03 & .03 \\
\hline \multicolumn{7}{|l|}{ Community resources } \\
\hline Sense of community & & & & & -.04 & -.04 \\
\hline Neighborhood attachment & & & & & -.02 & -.01 \\
\hline Support from friends & & & & & .03 & .03 \\
\hline \multicolumn{7}{|l|}{ Interactions } \\
\hline $\begin{array}{l}\text { Marital disagreements } \times \text { social } \\
\text { incoherence }\end{array}$ & & & & & & $.05^{* * * *}$ \\
\hline $\begin{array}{l}\text { Household demands } \times \text { friend } \\
\text { demands }\end{array}$ & & & & & & .02 \\
\hline $\begin{array}{l}\text { Children's problems } \times \text { unsafe } \\
\text { neighborhood }\end{array}$ & & & & & & -.04 \\
\hline$R^{2}$ & .079 & .295 & .322 & .327 & .329 & .333 \\
\hline Change in $R^{2}$ & .079 & .216 & .027 & .005 & .002 & .004 \\
\hline$F$ for change in $R^{2}$ & $33.26^{* *}$ & $119.56^{* * * *}$ & $20.32^{* * *}$ & $3.16^{*}$ & 1.40 & $3.21 *$ \\
\hline
\end{tabular}

Note: Standardized regression coefficients are presented.

$* p<.05 ; * * p<.01 ; * * p<.001$ (two-tailed tests).

demand or resource. Mean centering was used for the variables included in the cross-product terms. Twelve equations were computed for family-to-work conflict (4 family demands $\times 3$ community demands) and 12 for family-to-work facilitation ( 4 family resources $\times 3$ 


\section{TABLE 3}

Regressions of Family-to-Work Facilitation on Demographic Characteristics, Family and Community Demands, and Family and Community Resources $(N=1567)$

\begin{tabular}{|c|c|c|c|c|c|c|}
\hline Variables & Model 1 & Model 2 & Model 3 & Model 4 & Model 5 & Model 6 \\
\hline \multicolumn{7}{|l|}{ Demographic characteristics } \\
\hline Gender $(1=$ male $)$ & .02 & -.03 & -.05 & $-.08 * *$ & $-.06^{*}$ & $-.06^{*}$ \\
\hline Age & .05 & -.05 & -.04 & -.05 & $-.06^{*}$ & $-.06^{*}$ \\
\hline Education & .02 & .04 & .02 & $.05^{*}$ & $.05^{*}$ & $.05^{*}$ \\
\hline Child 6 or younger $(1=$ yes $)$ & .01 & .02 & .02 & -.00 & .00 & .00 \\
\hline \multicolumn{7}{|l|}{ Family demands } \\
\hline Marital disagreements & & $-.22 * * *$ & $-.22 * * *$ & -.02 & -.02 & -.02 \\
\hline Household demands & & $-.21 * * *$ & $-.20 * * *$ & $-.11 * * *$ & $-.11 * * *$ & $-.11 * * *$ \\
\hline Children's problems & & .00 & .00 & .03 & .04 & .03 \\
\hline Kin demands & & .00 & -.00 & .02 & .02 & .02 \\
\hline \multicolumn{7}{|l|}{ Community demands } \\
\hline Social incoherence & & & $-.08 * *$ & -.04 & -.02 & -.02 \\
\hline Unsafe neighborhood & & & .00 & $.05^{*}$ & $.06^{*}$ & $.06^{*}$ \\
\hline Friend demands & & & .02 & .01 & -.00 & .00 \\
\hline \multicolumn{7}{|l|}{ Family resources } \\
\hline Spouse support & & & & $.33^{* * * *}$ & $.32 * * *$ & $.33 * * *$ \\
\hline Household rewards & & & & $.25^{* * *}$ & $.23^{* * *}$ & $.23^{* * *}$ \\
\hline Parenting rewards & & & & $.06^{*}$ & .04 & .04 \\
\hline Kin support & & & & $.05^{*}$ & .02 & .03 \\
\hline \multicolumn{7}{|l|}{ Community resources } \\
\hline Sense of community & & & & & $.12 * * *$ & $.12 * *$ \\
\hline Neighborhood attachment & & & & & .02 & .02 \\
\hline Support from friends & & & & & .01 & .03 \\
\hline \multicolumn{7}{|l|}{ Interactions } \\
\hline $\begin{array}{l}\text { Spouse support } \mathrm{x} \text { friend } \\
\text { support }\end{array}$ & & & & & & $.06^{*}$ \\
\hline $\begin{array}{l}\text { Kin support x friend } \\
\text { support }\end{array}$ & & & & & & .03 \\
\hline$R^{2}$ & .003 & .114 & .120 & .294 & .308 & .312 \\
\hline Change in $R^{2}$ & .003 & .111 & .006 & .174 & .014 & .005 \\
\hline$F$ for change in $R^{2}$ & 1.20 & $48.93 * * *$ & $3.30 *$ & $95.65^{* * *}$ & $10.21^{* * *}$ & $5.09 * *$ \\
\hline
\end{tabular}

Note: Standardized regression coefficients are presented.

$* p<.05 ; * * p<.01 ; * * p<.001$ (two-tailed tests).

community resources). Interaction terms that were statistically significant in these equations were included in Model 6 of Tables 2 and 3. Graphing was used as a basis for interpretation; however, because of the weakness of the interactions, the graphs are not shown.

Model 1 in Table 2 indicates that family-to-work conflict is higher for women, younger respondents, and those with higher levels of 
education and with a child 6 or younger. Model 1 in Table 3 indicates that none of the demographic characteristics is associated with familyto-work facilitation.

Hypothesis 1a predicts that family demands will be positively related to family-to-work conflict, whereas they will be unrelated to or show weak negative relationships to family-to-work facilitation. As predicted, Model 2 in Table 2 reveals that all four family demands are positively associated with family-to-work conflict. These relationships are maintained when additional variables are added to the equations in Models 3-6. Family demands explain 21.6\% of the variance in family-to-work conflict. Model 2 in Table 3 shows that spouse and household demands are negatively related to family-to-work facilitation, whereas children's problems and kin demands are not related to facilitation. The relationship between marital disagreements and family-to-work facilitation is eliminated when family resources are added to the equation in Model 4, whereas the relationship between marital demands and facilitation is reduced but not eliminated when family resources are included. Family demands explain $11.4 \%$ of the variance in family-to-work facilitation. These findings provide modest support for Hypothesis 1a. Family demands are positively related to family-to-work conflict. With the exception of spouse and household demands, relationships between family demands and family-to-work facilitation are weak.

Hypothesis $1 \mathrm{~b}$ posits that community demands will be positively related to family-to-work conflict, whereas they will be unrelated to or show weak negative relationships to family-to-work facilitation. Model 3 in Table 2 documents that two of the three community demands, social incoherence and friend demands, are positively related to family-to-work conflict. However, the relationship for an unsafe neighborhood is weak and not statistically significant. Community demands explain an additional $2.7 \%$ of variance in family-to-work conflict. As predicted, Table 3, Model 3, indicates that community demands show relatively weak associations with family-to-work facilitation. The statistically significant negative relationship between social incoherence and facilitation is reduced when family and community resources are added to the equations. However, an unsafe neighborhood becomes positively related to facilitation when family and community resources are included in the equations. Community demands explain an additional $.6 \%$ of variance in facilitation. The findings provide modest support for Hypothesis $1 b$.

Hypothesis 1c suggests that community demands will exacerbate positive relationships between family demands and family-to-work 
conflict. Only three interaction terms were statistically significant in the initial analyses. Of these, only one remains significant in the final equation (Table 2, Model 6). It indicates that social incoherence exacerbates the relationship between marital disagreements and family-to-work conflict. Thus, Hypothesis 1c is not supported.

Hypothesis 2a proposes that family resources will be positively related to family-to-work facilitation, whereas they will be unrelated to or show weak negative relationships to family-to-work conflict. As predicted, family resources show consistent statistically significant positive relationships to family-to-work facilitation (Table 3, Model 4). However, the relatively weak relationships between facilitation and parenting rewards and kin support are reduced further when community resources are included in Model 5. Family resources explain $17 \%$ of the variance in family-to-work facilitation. With the exception of spouse support, family resources are not related to family-to-work conflict (Table 2, Model 4); they explain only an additional .5\% of the variance in family-to-work conflict. The findings support Hypothesis 2a.

Hypothesis $2 \mathrm{~b}$ predicts that community resources will be positively related to family-to-work facilitation, whereas they will be unrelated to or show weak negative relationships to family-to-work conflict. Table 3, Model 5, indicates that only one of the three community resources, sense of community, shows the predicted statistically significant positive relationship to facilitation. Neighborhood attachment and friend support are not related to facilitation. Community resources explain $1.4 \%$ of additional variance in facilitation. As expected, community resources are not related to family-to-work conflict (Table 2, Model 5); they explain only .2\% of variance. Thus, Hypothesis $2 \mathrm{~b}$ received limited support.

Hypothesis 2c states that community resources will amplify positive relationships between work resources and work-to-family facilitation. Only two interaction terms were statistically significant in the initial analyses and only one remains significant in Table 3, Model 6. Friend support amplifies the positive relationship between spouse support and family-to-work facilitation. The hypothesis is not supported.

\section{Discussion}

The purpose of this study was to examine the relative salience of family and community demands and resources in relation to family-towork conflict and facilitation. The study extends previous research in 
several directions. First, it focuses on family-to-work conflict and facilitation, rather than the more frequently studied work-to-family conflict and facilitation. Second, it includes facilitation in addition to conflict, thereby providing much needed data on enhancing processes associated with the work-family interface. Third, it includes family demands and resources not considered in earlier research using the MIDUS data (Grzywacz \& Marks, 2000). Fourth, it incorporates community demands and resources as additional possible sources of family-to-work conflict and facilitation. It also builds on a previous study by Voydanoff (2004a), who examined work and community demands and resources in relation to work-to-family conflict and facilitation.

The study is based upon a differential salience approach, which proposes that family, community, and work demands are relatively strongly related to work-family conflict, whereas resources are more strongly associated with work-family facilitation. The Voydanoff (2004a) study supported this approach for work and community demands and resources in relation to work-to-family conflict and facilitation. The findings of the present study generally support the differential salience approach for family and community demands and resources in relation to family-to-work conflict and facilitation. Family demands show relatively strong positive relationships to family-to-work conflict, whereas family resources show relatively strong positive relationships to family-to-work facilitation. However, the finding that spouse and household demands are negatively related to family-to-work facilitation as well as being positively related to conflict suggests that spillover processes may have cross-over effects between demands and facilitation. In addition, the negative relationship between spouse support and conflict is statistically significant. Thus, some demands are able to limit facilitation, whereas some resources are able to reduce conflict. The differential salience approach does not preclude such limited cross-over effects of resources on conflict or demands on facilitation. Instead, it emphasizes that the dominant pattern of effects is from demands to conflict and from resources to facilitation.

Because previous research is so limited, no specific hypotheses were proposed regarding possible similarities or differences by specific type of family role or activity, that is, spouse, household, parenting, or kin. The findings indicate that each of the four family role dimensions is relevant to family-to-work conflict and facilitation. However, the pattern of the findings differs across role dimensions. The resources associated with the spouse and household roles are more strongly 
related to facilitation than are those associated with parenting and kin roles. The marital relationship and household activities are core aspects of family life, whereas relationships with extended kin are more variable among diverse types of families. However, the relative weakness of relationships for parenting demands and resources is puzzling. It may be due in part to the narrowness of the measures. Children's problems are only one aspect of the demands associated with parenting over the life course. In addition, the measure of parenting rewards is limited. The measures needed to assess the range of parenting demands and resources would need to incorporate the diversity associated with rearing children of different ages. This variation by age of the child is documented by the positive relationship between having a child 6 or younger in the home and family-to-work conflict. More specific information could be obtained by having detailed measures of the amount of time spent in the four family activity arenas. Additional research is needed that includes a more comprehensive range of variables that can assess more specifically the processes associated with each role dimension in relation to family-towork conflict and facilitation.

As expected, the differential salience approach receives stronger support for family demands and resources than for community demands and resources. However, the findings do provide some support for the relative salience of community demands for conflict and community resources for facilitation. Two of the three community demands, social incoherence and friend demands, are more strongly related to conflict than facilitation, whereas the findings for an unsafe neighborhood are mixed. An unsafe neighborhood shows a weak positive relationship to conflict; however, it also is positively related to facilitation. The reason for this is unclear, especially since the zeroorder correlation is weakly negative. One possible explanation is that the measure of an unsafe neighborhood is a very limited indicator of neighborhood demands. Only one community resource, sense of community, is positively associated with family-to-work facilitation.

The idea that community demands and resources may moderate relationships between family demands and resources and family-towork conflict and facilitation is not supported in this study. Support for exacerbating effects is limited to the effects of social incoherence on the relationship between marital disagreements and family-to-work conflict. The lone amplifying effect indicates that friend support amplifies the positive relationship between spouse support and familyto-work facilitation. None of the interactions explain even $1 \%$ of the variance in conflict or facilitation. Further research is needed to 
determine the extent to which community factors moderate relationships between family demands and resources and conflict and facilitation.

The examination of community factors in relation to the workfamily interface is in its early stages. This study has focused on three aspects of community: community integration, neighborhood safety and attachment, and friend demands and support. The findings suggest that family and community demands and resources have additive effects on family-to-work conflict and facilitation. However, other community demands and resources also may be important in relation to family-to-work conflict and facilitation. These include the level of participation in community organizations and informal community activities, the extent to which communities provide formal programs and services needed by working families, the amount and types of informal community supports provided to working families, social or physical isolation, the availability of transportation to and from work, and a physical layout that makes it easy or difficult to access needed services. Additional studies are needed to explore the influence of these community demands and resources on work-family conflict and facilitation.

It also is important for future research to explicitly examine familyto-work conflict and facilitation as mediators of relationships between family and community demands and resources and work outcomes. This study did not have adequate measures of work outcomes to make such an analysis. A few studies have found that family-to-work conflict mediates relationships between a limited range of family demands and work outcomes (Aryee, Fields, \& Luk, 1999; Frone, Russell, \& Cooper, 1992; Frone et al., 1997; but see Grandey \& Cropanzano, 1999). Additional work is needed to examine the mediating effects of familyto-work conflict with a broader range of demands and work outcomes. No studies were located that examine family-to-work facilitation as a mediator of relationships between family and community resources and work outcomes.

As Frone (2003) has suggested, we need to understand more about the sources of family-to-work conflict because of its implications for work outcomes and policies oriented toward improving work performance and motivation through reducing conflict. The same may hold for family-to-work facilitation. Improving job performance and motivation may depend as much on increasing family-to-work facilitation as reducing family-to-work conflict. This paper has taken an important step by looking at how family and community demands and resources have differential effects on family-to-work conflict and 
facilitation. It provides useful information for those designing programs and policies to reduce family-to-work conflict and increase family-to-work facilitation. Additional work will expand further our understanding of ways to reduce family-to-work conflict and increase family-to-work facilitation, thereby improving the quality of work and family life.

\section{References}

Adams, G. A., King, L. A., \& King, D. W. (1996). Relationships of job and family involvement, family social support, and work-family conflict with job and life satisfaction. Journal of Applied Psychology, 81, 411-420.

Aryee, S., Fields, D., \& Luk, V. (1999). A cross-cultural test of a model of the work-family interface. Journal of Management, 25, 491-511.

Beauregard, T. A. (2002, August). Can work domain variables predict family interference with work? Seattle: Paper presented at the annual meetings of the Academy of Management.

Boyar, S. L., \& Maertz, C. P. Jr. (2003, April). Work-family conflict: The mediating effect of work and family demand. Orlando: Paper presented at the annual meetings of the Society for Industrial and Organizational Psychology.

Carlson, D. S., \& Kacmar, K. M. (2000). Work-family conflict in the organization. Journal of Management, 26, 1031-1054.

Demerouti, E., Bakker, A. B., Nachreiner, F., \& Schaufeli, W. B. (2001). The job demands-resources model of burnout. Journal of Applied Psychology, 86, 499-512.

Edwards, J. R., \& Rothbard, N. P. (2000). Mechanisms linking work and family. Academy of Management Review, 25, 178-199.

Frone, M. R. (2003). Work-family balance. In J. C. Quick, \& L. E. Tetrick (Eds.), Handbook of occupational health psychology (pp. 143-162). Washington, DC: American Psychological Association.

Frone, M. R., Russell, M., \& Cooper, M. L. (1992). Antecedents and outcomes of workfamily conflict. Journal of Applied Psychology, 77, 65-78.

Frone, M. R., Yardley, J. K., \& Markel, K. S. (1997). Developing and testing an integrative model of the work-family interface. Journal of Vocational Behavior, 50, $145-167$.

Grandey, A. A., \& Cropanzano, R. (1999). The conservation of resources model applied to work-family conflict and strain. Journal of Vocational Behavior, 54, 350370.

Greenhaus, J. H., \& Beutell, N. J. (1985). Sources of conflict between work and family roles. Academy of Management Journal, 10, 76-88.

Greenhaus, J. H., Powell, G. N. (in press). When work and family are allies. Academy of Management Review.

Grzywacz, J. G., \& Marks, N. F. (2000). Reconceptualizing the work-family interface. Journal of Occupational Health Psychology, 5, 111-126.

Keyes, C. L. (1998). Social well-being. Social Psychology Quarterly, 61, 121-140.

Kowalski, K. B., \& Beauvais, L. L. (2001, August). A model of the antecedents of workfamily conflict and family-work conflict as moderated by social support. Washington: Paper presented at the annual meetings of the Academy of Management.

Lazarus, R. S., \& Folkman, S. (1984). Stress, appraisal, and coping. New York: Springer.

McMillan, D. W., \& Chavis, D. M. (1986). Sense of community. American Journal of Community Psychology, 27, 75-105. 
Montgomery, A. J., Peeters, M. C. W., Schaufeli, W. B., \& Den M. Ouden (2003). Workhome interference among newspaper managers. Anxiety, Stress, and Coping, 16, $195-211$.

Piotrkowski, C. (1979). Work and the family system. New York: Free Press.

Rothbard, N. P. (2001). Enriching or depleting? The dynamics of engagement in work and family roles. Administrative Science Quarterly, 46, 655-684.

Schuster, T. L., Kessler, R. C., \& Aseltine, R. H. (1990). Supportive interactions, negative interactions, and depressed mood. American Journal of Community Psychology, 18, $423-438$.

Sumer, H. C., \& Knight, P. A. (2001). How do people with different attachment styles balance work and family?. Journal of Applied Psychology, 86, 653-663.

Voydanoff, P. (2002). Linkages between the work-family interface and work, family, and individual outcomes. Journal of Family Issues, 23, 138-164.

Voydanoff P. (2004a). Implications of work and community demands and resources for work-to-family conflict and facilitation. Journal of Occupational Health Psychology, 9, 275-285.

Voydanoff, P. (2004b). The effects of work and community resources and demands on family integration. Journal of Family and Economic Issues, 25, 7-23.

Voydanoff, P. (2004c). The effects of work demands and resources on work-to-family conflict and facilitation. Journal of Marriage and Family, 66, 398-412.

Woldoff, R. A. (2002). The effects of local stressors on neighborhood attachment. Social Forces, 31, 87-116. 
Reproduced with permission of the copyright owner. Further reproduction prohibited without permission. 